\title{
O estatuto das sociedades anônimas brasileiras *
}

\author{
Waldemar Ferreira \\ Professor Emérito da Faculdade de Direito \\ da Universidade de S. Paulo e Honorário \\ da Universidade do Rio Grande do Sul.
}

1. Leis não se improvisam. As por que os povos se regem, ainda quando suas instituições políticas se modifiquem, em regra subsistem e sòmente se alteram por ação do tempo e das contingências sociais e econômicas. O exemplo da Turquia, tomando de empréstimo os códigos suiços por efeito da revolução política que a ocidentalizou, ainda é impar.

Quando em 1822 a colônia portuguêsa da América se proclamou independente, rompendo os laços metropolitanos e convolando-se no Império do Brasil, o príncipe, que o regia, aclamado Imperador, declarou em vigor no país as Ordenações, leis, regimentos, alvarás, decretos e resoluções promulgados pelos reis de Portugal e pelos quais a nação se governara até 25 de abril de 1821 , data em que seu augusto pai, Sua Magestade Fidelìssima D. João VI, se ausentara do Brasil, mais as que, como regente havia até então promulgado, "enquanto se não organizasse um novo Código, ou não fôssem especialmente alteradas"

2. As Ordenações do Reino, promulgadas em 1603 por D. FILIPE III, de Espanha, que detinha a Coroa de Portugal,

* De La Società per Azioni alla Metà del Secolo XX, Racolta di scritti in onore di Angelo Sraffa, Milão, 1960. 
e ficaram a vigorar no Brasil, eram complexas e abundantes. Compendiaram as leis costumeiras e foralícias implantadas pelos povos invasores da Península Ibérica e os preceitos advindos do Direito Romano e do Direito Canônico, que por cristalização e depuração já se haviam incorporado nas Ordenações Afonsinas de 1446 e nas Ordenações Manoelinas de 1512, mais as leis que ao depois se editaram. Constituiram por isso mesmo código amplo e completo, de singular originalidade desde sua versão primeira, confrontadas com os demais códigos continentais europeus, assim na estrutura formal, como especialmente na material.

Como era da época, as Ordenações Filipinas não distinguiram a matéria comercial da matéria civil, mantendo a unidade do direito privado. Não divisaram dessarte no objetivo não econômico de tais ou quais sociedades, ou no objetivo econômico de outras, constituídas com aspecto e finalidade lucrativa profissional, fundamento para dividí-las em duas categorias, as comerciais ao lado das sociedades civis.

No título Xurv do seu livro Iv, as Ordenações disciplinaram o "contrato da sociedade e companhia"; e esta epígrafe poderia originar a perspectiva de que nesta últíma expressão se houvesse compreendido a sociedade anônima ou por ações, qual se instituira, um ano antes, em 20 de março de 1602, na Holanda - a Companhia das Índias Orientais. Não teria isso sido possível por duas ordens de argumentos. É o primeiro que as Ordenações em 1602 já se achavam elaboradas pela comissão instituida por D. FILIPE II. E o segundo que a Companhia das Índias Orientais se havia organizado como arma de combate ao poderio da Coroa de Espanha, em guerra com a Holanda ${ }^{1}$. Elas desconheciam a sociedade anônima.

Mercê mesmo da formação da palavra companhia, esta designava a sociedade e a copulativa que as unia no título

1. Waldemar Ferreira, História do Direito Brasileiro, ed. Max Limonad, vol. III, São Paulo, 1955. 
as sinonimizava, de modo que uma e outra exprimiam o contrato que duas pessoas, ou mais, faziam entre si, ajuntando todos os seus bens, ou parte dêles, "para melhor negócio e maior ganho".

Seria a companhia, com êsse escopo, de dois tipos - a universal e a particular, aquela quando abrangesse todos os bens que os companheiros tivessem; e esta, quando não fôsse de todos os bens, "mas de parte dêles, assim como de certo trato, ou negócio".

Quer num, quer noutro tipo societário, os bens dos companheiros se comunicavam, entrando em regime de comunhão. Dizia-o o texto. "Se o contrato de companhia fôr feito entre algumas pessoas de todos os bens, que tiverem, logo o senhorio e posse de tais bens se traspassará recìprocamente nos companheiros, sem ser necessária alguma apreensão corporal, ou ato algum, por que se alcance senhorio, ou posse de alguma coisa. E tudo o que qualquer dos companheiros adquirir, depois de feita a tal companhia de todos os bens, por qualquer título que seja, se comunicará entre todos, e o domínio e posse dêles se traspassará nos ditos companheiros".

Estabelecia-se dessarte entre os companheiros estado de comunhão geral de bens trazidos para a companhia ou posteriormente adquiridos. Era o estado de comunhão societária. Não se dava o mesmo na companhia particular. Nesta, o estado de comunhão se adstringia aos bens trazidos para a companhia.

"Quando - rezavam as Ordenações - o contrato de companhia não fôr de todos os bens, mas de parte dêles, assim como de certo trato, ou negócio, aquilo sòmente se comunicará entre os companheiros, que cada um dêles houver por seu trabalho, ou indústria no mesmo trato, ou negócio, e não aquilo, que cada um dêles houver por outro modo fora da companhia por respeito de sua pessoa, - ou por benefício particular, que de alguém recebeu, assim como uma herança, ou legado, doação, ou outra coisa semeIhante". 
A companhia particular se distinguia da companhia universal, como é de ver, por ajuste expresso, em que se lhe predeterminasse a natureza, de molde a restringir o estado de comunhão societária aos bens e negócios que lhe constituissem o objeto. Dominava o princípio de que as restrições de direito deveriam ser expressas, a despeito de que as companhias pudessem constituir-se e sua existência comprovar-se até por via de testemunhos.

Não obstante a pobreza dos dispositivos atinentes ao contrato de sociedade e companhia, nos termos expostos, e a despeito de serem sinônimas estas duas expressões, companhias se organizaram em Portugal, incorporadas por cartas ou alvarás de instituição, concedidas pelo govêrno. Assim, houve a Companhia de Comércio da Índia, em 1633; e, em 1649, a Companhia Geral do Comércio do Brasil, e outras ao depois, sendo que esta, que foi a de mais longa duração, não apresentava o organismo da sociedade anônima, pois não era sociedade de acionistas, mas de comanditários ${ }^{2}$.

3. Ao elaborar-se o Código Comercial do Império do Brasil, promulgado pela lei . $^{\circ} 556$, de 25 de junho de 1850 , as condições econômicas do país, mal saído do regíme colonial que nele vedara a criação de indústrias e fábricas, propiciaram a criação destas. Não poucas houveram de adotar as vestes das sociedade anônimas, a despeito da inexistência de paradigma adequado e de mui sucintamente reguladas naquele código.

Não foram, a respeito destas, necessários mais do que cinco artigos. Preceituou-se no primeiro que aquelas sociedades se designariam pelo objeto ou emprêsa a que se destinassem, sem firma social, administrando-se por mandatários revogáveis; mas sòmente se poderiam estabelecer por tempo determinado e com autorização do govêrno, de-

2. Waldemar Ferreira, A Companhia Geral do Comércio do Estado do Brasil, ed. do Jornal do Fôro, Lisboa. 1956. 
pendente de aprovação do Corpo Legislativo, quando houvessem de gozar de algum privilégio. Provar-se-iam por escritura pública, ou pelos estatutos, e pelo ato do poder público que as houvesse autorizado, inscritos no registro do comércio e publicados pelo Tribunal do Comércio antes que começassem a operar. Desmanchando-lhes a estrutura, os artigos subsequentes disseram que o seu capital se dividiria em ações e estas em frações, podendo ser ao portador, transmissíveis por endôsso e por ato lançado nos registros da companhia. Os sócios não responderiam por mais do valor das ações ou interêsse por que se houvessem comprometido. Os administradores ou diretores responderiam pessoal e solidàriamente a terceiros, que com elas tratassem, até ao momento em que as inscrevessem no registro do comércio; depois disso, só responderiam pela execução do mandato.

Era pouco, evidentemente; mas muito mais do que isso não haviam prescrito os códigos até então promulgados, a começar pelo de França. Em face dêste, como em face do código do Brasil, as sociedades anônimás ficaram na dependência governamental. A propósito daquele, observou Georges Ripert que a autorização do govêrno não era de pura forma, pois o Conselho de Estado devia manifestar-se e tinha fixado estatutos típicos e tornado obrigatória sua adoção. Exigia principalmente que a administração da sociedade se confiasse a mandatários indestituíveis, designados nos estatutos. Era o meio de encarnar a sociedade em seus dirigentes, personalizando-as, de modo que os interessados se viam em palpos de aranha diante da exigência da integralização do capital, a que os subscritores se opunham, antes de obtida a autorização do govêrno, que era suscetível de revogação em caso de violação dos estatutos. Dizia então que as sociedades anônimas se achavam sob a tutela do Estado: a confiança, que despertavam, era a confiança aberta ao Estado ${ }^{3}$.

3. GEORgeS RIPERT, Aspects juridiques du capitalisme moderne, pág. 55, n. 23. 
Diferente não era no Brasil. Embora, observou PimenTA Bueno, "embora uma emprêsa ou sociedade pröjetada em nada contrarie a lei e a boa fé comercial, embora tenha tôdas as probalidades de ser bem sucedida, embora as pessoas dos empresários e subscritores ministrem tôdas as garantias desejáveis, embora sejam satisfeitas tôdas as condições do decreto de 10 de janeiro de 1849 , basta que a Ministério julgue que a pretenção prejudica os interêsses da indústria em geral, ou algum interêsse do Tesouro, que promove a agiotagem, ou que encerra qualquer inconveniente, para impôr a seu veto" Mesmo depois de obtida a autorização se tinha que sofrer "um processo longo e humilhante pela dependência ministerial, que é fatigante e quase fabulosa, que gasta meses e até ano, que desconcerta todos os planos e causa perdas que podem ser consideráveis" 4 .

Eram essas dificuldades decorrência da legislação deficiente das sociedades anônimas, que aumentava a desconfiança que elas inspiravam por não bem conhecidas dos que deviam manifestar-se sôbre seus atos constitutivos, examinando-lhes a estrutura e o objetivo, afim de apreciar-înes as probabilidades de sucesso, dada a particularidade de ser nelas limitada a responsabilidade de seus fundadores e sócios.

Êsses empecilhos, que legislação esparsa e de efeitos transitórios, mercê de crises financeiras que abalaram o país, não lograram desfazer, nem diminuir, ensejaram movimento entre os homens de negócios, patrocinados pelos juristas, no sentido de libertar as sociedades anônjmas da tutela governamental.

4. A campanha libertadora das sociedades anônimas explodiu, em 1882, nos trabalhos parlamentares. Estabeleceu-se então que elas deveriam ter por fundamento uma

4. José Antônio Pimenta Bueno, Direito Público Brasileiro e Análise da Constituição do Império, ed. de J. Villeneuve \& Cia., Rio de Janeiro, 1857, pág. 408, n. 558. 
trilogia - liberdade, publicidade e responsabilidade, fora da qual não haveria senão restrições injustificáveis ao direito individual. A liberdade permitiria que o espírito de iniciativa tivesse o desenvolvimento de que fôsse capaz, acomodando-se às conveniências e necessidades dos sócios e do bem público. A publicidade do projeto e dos estatutos sociais e das condições de vida e de movimento dos acionistas em busca do objetivo proposto e das particularidades das transações e negócios que o constituiriam, serviria para prevenir e afastar perigos a que pudessem estar sujeitos quantos de boa fé pretendessem aplicar seus capitais. A responsabilidade efetiva dos fundadores e dos diretores que lhes sucedessem na gestão dos negócios da emprêsa, estabelecida em têrmos eficazes no civil e no criminal, seria de molde a fornecer a devida garantia ao público em geral e aos acionistas em particular.

Sob a êgide dêsses princípios, chegou-se à lei n. ${ }^{\circ} 3.150$, de 4 de novembro de 1882 , a que deu regulamento o decreto n. $^{\circ} 8.821$, de 30 de dezembro de 1882 , estabelecendo que as companhias ou sociedades anônimas, quer seu objeto fôsse comercial, quer civil, se poderiam estabelecer sem autorização do govêrno. Não se constituiriam sem esta todavia, dada legislativamente, os bancos de circulação. Dela careceriam as sociedades anônimas que tivessem por objeto o comércio ou fornecimento de gêneros ou substâncias alimentares e as sociedades anônimas estrangeiras que pretendessem funcionar no país.

5. Distinguir-se-iam as sociedades anônimas das demais espécies de sociedades:

a) pelo concurso de, ao menos, sete sócios;

b) pela divisão de seu capital em ações e destas em frações;

c) pela responsabilidade limitada dos acionistas.

I. Pretendeu-se, na elaboração parlamentar da lei, admitir que as sociedades anônimas se pudessem constituir com qualquer número de sócios, dois no mínimo. Prevaleceu no entanto o número mínimo de sete subscritores do 
capital social. Só depois dêste assim subscrito e de depositada a sua décima parte em dinheiro do valor de cada ação, elas poderiam constituir-se, por escritura pública, lavrada por notário, ou por deliberação dos subscritores em assembléia geral.

O número mínimo de sete sócios ou acionistas deverse-ia manter durante tôda a vida das sociedades anônimas, sob pena de dissolução, se dentro do prazo de seis meses não se preenchesse o setenato. Esse semestre de convalescimento se contaria, se tôdas as ações fôssem nominativas, da data em que, pela publicação das transferências, se verificasse a redução dos acionistas a menos de sete; e, se ao portador ou transferíveis por endôsso, do dia da assembléia geral em que se verificasse aquela redução.

Sociedades anônimas, devidamente constituídas, não poderiam entrar em funções e praticar vàlidamente ato algum senão depois de arquivar na Junta Comercial e, onde inexistisse, no Registro de Hipotecas da comarca, os seus atos constitutivos, a saber:

a) os estatutos ou a escritura contendo o contrato social e a constituição da sociedade;

b) a lista nominativa dos subscritores, indicando o número de ações e as entradas de cada um;

c) a certidão do conhecimento de depósito da décima parte do capital social;

d) a ata da constituição da sociedade.

Não se arquivariam os atos constitutivos de sociedades cujo objeto fôsse contrário à lei, à moral e aos bons costumes.

Publicar-se-iam nos jornais do têrmo ou lugar mais próximo e no Diário Oficial da Província os estatutos ou a escritura do contrato social, declarando a data de seu arquivamento e os nomes, profissões e moradas dos administradores; e o jornal oficial se arquivaria no Registro de Hipotecas da comarca.

II. Dividir-se-ia o capital social em ações de igual valor, e cada ação poder-se-ia dividir em frações, caso em 
que as frações, reunidas em número que desse valor equivalente ao de uma ação, se considerariam como ação, conferindo aos respectivos portadores, em conjunto, os direitos que tinham a ação por base e unidade.

As ações poderiam ser ao portador, desde que integralizadas, e nominativas, ou transferíveis por endôsso. A propriedade das nominativas se estabeleceria pela inscrição no livro do registro e se transferiria por têrmo nesse mesmo livro; das ao portador, pela tradição manual; e a das por endôsso, por via dêste, lançado no verso de cada título.

Firmou-se o princípio de que às sociedades anônimas não seria lícito negociar as próprias ações, adquirindo-as ou vendendo-as, nem recebê-las em penhor, salvo em caução das responsabilidades de seus diretores. Penhoráveis seriam no entanto suas ações pelos próprios acionistas em garantia de obrigações próprias, se nominativas por via de têrmo nos livros da companhia, se ao portador ou endossáveis pela forma comum do penhor. Êste não inibiria aos acionistas no entanto do exercício dos direitos que lhes eram próprios, quais os da participação nos dividendos sociais e os de participação e voto nas deliberações das assembléias gerais.

III. Se desenvolta não se mostrou a lei no disciplinar os direitos e obrigações dos acionistas, acentuou todavia que não responderiam pelas obrigações sociais além do valor nominal das ações que subscrevessem ou viessem a adquirir.

6. Estruturando os órgãos sociais, tripartiu-os a lei, criando o administrativo, o deliberativo e o fiscalizador e dando-lhe dessarte organismo democrático.

I. A administração social caberia a dois ou mais diretores, acionistas ou não, gratuitos ou assalariados, eleitos pela assembléia geral por tempo não superior a seis anos, reelegíveis, mas destituíveis a qualquer tempo sem necessidade de justificação de causa. 
O número, modo e condições eletivas dos diretores, seus vencimentos, prazo de mandato, destituição e substituição, regular-se-iam nos estatutos ou contrato social. Adotaria cada sociedade o regime administrativo que lhe parecesse mais conveniente. Em caso de omissão estatutária, reputar-se-iam os administradores investidos de poderes para a prática dos atos de gestão e de representação đa sociedade em Juízo, ativa e passivamente; e para a nomeação dos que os auxiliassem na gestão diária dos negócios, respondendo pelos atos dêstes, como se fôssem próprios.

Sem especiais poderes vedados se achariam os administradores de transigir, renunciar direitos, hipotecar ou empenhar bens sociais; ou contrair obrigações e alienar bens e direitos, salvo quanto aos atos e contratos constituintes do objeto social.

Nessas condições, os diretores não responderiam pessoal, individual ou solidàriamente pelas obrigações contraídas em nome da sociedade. Esta se obrigaria pelo ministério dêles, como seus órgãos estatutários; mas ao revês, responderiam êles para com ela quando agissem com negligência, culpa ou dolo; para com ela terceiros prejudicados, pelo excesso de mandato; e, solidàriamente, a ela e a êstes, pelos prejuízos e danos decorrentes da infringência da lei e dos estatutos.

II. A assembléia geral dos acionistas, como órgão supremo da vontade social, fruía de poderes para a resolução de todos os negócios sociais e para a tomada de decisões de qualquer natureza, condizentes com o seu interêsse, inclusive a alteração ou reforma dos estatutos ou contrato social.

Traçou a lei as regras para sua convocação, instalação, funcionamento, poder deliberante dos votos dos acionistas; mas nos estatutos se determinaria a ordem a observar-se nelas, bem assim o número de ações que deveria possuir cada acionista para exercer o direito de voto em razão do número de ações, que possuisse, sem prejuízo do direito de comparecimento e de discussão da matéria da ordem do dia. 
III. Tôda sociedade anônima deveria ter um conselho composto de três ou mais fiscais, eleitos pela assembléia geral ordinária, que se realizaria anualmente. Os fiscaîs teriam direito para, durante o semestre precedente à assembléia geral ordinária, examinar os livros da companhia, verificar o estado de caixa e exigir informações dos diretores, a fim de apresentar àquela assembléia parecer sôbre os negócios e operações sociais, tomando por base o inventário, o balanço e as contas dos administradores.

7 Afastou a lei as sociedades anônimas, da falência instituindo para elas, em caso de insolvabilidade, de cessação de pagamento das dívidas e da perda de três quartos de seu capital, processo especial: o de liquidação forçada. Insujeitas dessa forma à falência as companhias, seus administradores e sócios responderiam no entanto pelos crimes que, como tais, cometessem contra a própria sociedade ou contra terceiros.

Criou-se dessarte processo especial para a falência das sociedades anônimas, sem que como tal se chamasse, mas no qual a decisão declaratória da liquidação forçada produziria efeitos idênticos aos da sentença falimentar; e, ademais, naquele processo, seria possivel até a apresentação de proposta de concordata, desde que autorizada por acionistas que representassem no mínimo dois terços do capital social.

Constituía isso particularidade digna de nota, logo depois desaparecida, com a submissão das sociedades anônimas à falência, com a só restrição, mui recente, das destinadas ao comércio bancário, suscetíveis de liquidação extrajudicial, na órbita administrativa.

8. Eis, em súmula, como, há setenta e quatro anos, se estabeleceu o estatuto das sociedades anônimas brasileiras, em regime de liberdade de constituição e de funcionamento. Não se predeterminou siquer quantia mínima para o capital de tais sociedades ou para o valor nominal das 
ações em que se dividisse. A escolha do tipo e das vestes societárias das emprêsas ficou ao inteiro arbítrio de seus fundadores; e os atos constitutivos ficaram sobremodo facilitados, sobretudo para as companhias que viessem a organizar-se sem a subscrição pública de seu capital.

Em decurso de tempo de alguma longura, como o escoado de 1882 até agora, aquela lei de 1882 sofreu alterações e acréscimos requeridos pelas contingências da vida econômica e financeira do país, ao compasso dos eventos políticos de tão variado rumo nos últimos tempos, que impuseram modificações ao anonimato, sem quebra todavia de seu organismo naquele tempo delineado.

Se, estruturalmente, a sociedade anônima é sempre a mesma, onde quer que ela se forme, tem ela estatuto específico, que as diversas leis, que ùltimamente a disciplinaram em vários países, não deformaram. Foi o que aconteceu no Brasil com a reforma levada a efeito pelo decreto-lei n. ${ }^{\circ}$ 2.627, de 26 de setembro de 1940, ainda agora vigente, com pequenas alterações introduzidas por leis posteriores. É que êsse diploma legislativo foi tradicionalista e sòmente modificou o que demandava alteração.

São consideráveis realmente as modificações que se tem procurado infiltrar no anonimato, em tôda a parte, a começar pelo conceito do acionista. A lei brasileira via nele mais que o titular da ação, o sócio; e assim o qualificava, por não dever ser estranho à sociedade anônima a affectio societatis, por serem todos os que nela intervêm, em regra, ligados por laços de negócios, quando não de parentesco, verdadeiramente, sociedade de família. Há, certamente, no Brasil, inúmeras sociedades que escapam a essa contingência; mas a verdade é que proliferam as sociedades anônimas, que se dizem sociedades fechadas, por pertencentes a certos e determinados grupos, as ações, senão em totalidade, em grande maioria. Acionistas preponderantes delas se apoderam e nelas exercem sua vontade. Gerem-nas ao seu talante, quer existindo acionistas reais, quer servindo-se de acionistas fictícios, empregados ou amigos. 
De resto, reconhecendo a constância da prática, a lej transigiu com ela e consagrou a existência da sociedade de um só acionista sem perda de sua personalidade jurídica. Dissolve-se realmente a que tenha menos de sete acionistas, seis ou apenas um; mas essa dissolução se dá, "pela redução do número de acionistas a menos de sete, verificada em assembléia geral ordinária, e caso êsse mínimo não seja preenchido até a seguinte assembléia geral ordinária".

Reduzindo-se a um o número de acionistas no dia subsequente ao da assembléia geral ordinária, êsse fato sòmente produzirá efeito depois de constatado na subsequente assembléia geral ordinária a realizar-se daí a um ano; e como mais um ano decorrerá para o convalescimento da sociedade, esta entrará então em período agônico, sem que todavia sua personalidade jurídica desapareça, o que acontecerá de pleno direito se o número mínimo não se preencher.

Fácil será preenchê-lo e dar a impressão de restauração da sociedade; mas é de imaginar quão graves problemas poderão surgir nesse entretempo.

9. De qualquer modo que seja, é evidente que sete sócios poderão constituir a sociedade e mantê-la, pouco importando sua nacionalidade. Brasileiros e estrangeiros os acionistas, ainda assim como brasileira se reputará a sociedade. São nacionais, ao dizer da lei, as sociedades organizadas na conformidade de seus dispositivos, que no país tenham a sede de sua administração. Pouco importa a nacionalidade de seus acionistas: sete estrangeiros podem constituir no Brasil uma sociedade anônima brasileira, pela regra de que, mercê de sua personalidade jurídica, as sociedades são distintas de seus componentes.

De resto, e diga-se de passagem, a Constituição assegura a brasileiros e a estrangeiros residentes no país a igualdade perante a lei, pela inviolabilidade dos direitos concernentes à vida, à liberdade, à segurança individual e à propriedade. Sendo a todos dessarte livre a formação de associação, a própria Constituição estabeleceu casos 
particulares de restrições a direitos dos estrangeiros dómiciliados no país, nesse particular. E são poucos. As concessões ou autorizações para o aproveitamento dos recursos minerais e de energia hidráulica se conferirão exclusivamente a brasileiros ou a sociedades organizadas no país, assegurado ao proprietário preferência para explorá-los. A navegação de cabotagem para o transporte de mercadorias é privativa dos navios nacionais, salvo caso de necessidade pública; e os proprietários, armadores e comandantes de navios nacionais, bem como dois terços, pelo menos, dos seus tripulantes, devem ser brasileiros natos no Brasil, ainda que de pais estrangeiros, não residindo êstes a serviço de seu país, ou filhos de brasileiros ou brasileira, nascidos no estrangeiro, se os pais estiverem a serviço do Brasil; ou, não o estando, se vierem a residir no país e optarem pela nacionalidade brasileira dentro em quatro anos. É vedado a estrangeiros a propriedade de emprêsas jornalísticas, sejam políticas ou simplesmente noticiosas, assim como as radiodifusoras. Nem êsses, nem pessoas jurídicas, excetuados os partidos políticos, poderão ser acionistas de sociedades anônimas proprietárias dessas emprêsas; e as ações não poderão ser ao portador. A brasileiros natos caberá exclusivamente a responsabilidade principal delas e a sua orientação intelectual.

Afora em casos tais, a estrangeiros é lícito coparticipar de sociedades anônimas brasileiras, sendo que algumas carecerão de autorização governamental de autorização e funcionamento, ainda que constituídas exclusivamente de acionistas brasileiros. Não se podem constituir, sem que prèviamente autorizadas, sociedades, agências ou estabelecimentos de seguros, montepio, caixas econômicas, salvo as cooperativas e os sindicatos profissionais legalmente organizados; as de navegação de cabotagem e aérea; as de energia hidráulica; as de gêneros ou substâncias alimentares; e as de viagens e turismo.

Carecem de autorização de funcionamento no Brasil as sociedades anônimas estrangeiras: elas não podem, sem autorização do govêrno federal, funcionar no país, por si 
mesmas, ou por filiais, sucursais, agências ou estabelecimentos que as representem. Podem porém ser acionistas de sociedades anônimas brasileiras.

As sociedades anônimas estrangeiras autorizadas a funcionar ficarão sujeitas às leis e tribunais brasileiros quanto aos atos ou operações que praticarem no Brasil; e qualquer alteração que elas, em seu país de origem, fizerem nos seus estatutos dependerão de aprovação do govèrno federal para que produzam efeitos em território brasileiro.

10. No atinente às ações, conforme a natureza dos direitos ou vantagens que conferem a seus titulares, dividiu-as a lei em ordinárias ou comuns e em preferenciais, estas de uma ou mais classes, e as de gôzo ou fruição.

A preferência pode consistir na prioridade na distribuição de dividendos, mesmo fixos e cumulativos, e no reembolso do capital, com prêmio ou sem êle; ou, então, na acumulação dessas prioridades.

As ações de gôzo ou de fruição são as que substituem as ações amortizadas com fundos disponíveis e sem diminuição do capital.

Podem criar-se, a qualquer tempo, partes beneficiâiias, títulos negociáveis, sem valor nominal e estranhos ao capital social, conferindo aos seus proprietários direito de crédito eventual contra a sociedade, consistente em participação nos lucros líquidos anuais, que, segundo a lei e os estatutos, devam ser distribuídos pelos acionistas.

11. No capítulo das relações entre a sociedade anônima e seus acionistas, a lei fêz a declaração dos direitos próprios dos acionistas, em termos precisos.

Nem os estatutos sociais, nem a assembléia geral poderão privar qualquer acionista do direito:

a) de participar dos lucros sociais, observada a regra da igualdade de tratamento para todos os acionistas da mesma classe ou categoria;

b) de compartir, nas mesmas condições, do acervo social, no caso de liquidação da sociedade; 
c) de fiscalizar, pela forma estabelecida na lei, a gestão dos negócios sociais;

d) de preferência para a subscrição de ações novás, no caso de aumento do capital social, ou de ceder êsse direito a outro acionista, ou a terceiro;

e) de retirar-se da sociedade, quando vencido, nas deliberações da assembléia geral, na aprovação das matẻrias descriminadas na lei.

Com isso, deu-se garantia aos acionistas contra as deliberações de maiorias facciosas; e mais eficiente se tornou essa garantia com assegurar-se-lhes o dividendo minimo de $6 \%$ dos lucros anuais e a proibição das importâncias dos fundos de reserva criados pelos estatutos em caso algum ultrapassarem a cifra do capital social realizado. Atingido êsse total, a assembléia geral aplicará parte daquelas importâncias na integralização do capital, se fôr caso, ou no seu aumento, distribuindo as ações correspondentes pelos acionistas; ou partilhando-as a êstes, em dinheiro, a título de bonificação.

Com o mesmo objetivo, a lei padronizou o balanço anual da companhia, estabelecendo regras para a estimação do ativo, quer quanto aos bens destinados à exploração do objeto social, quer quanto aos valores mobiliários, matéria prima, bens destinados à alienação ou que constituam produtos ou artigos da indústria ou comércio da sociedade.

Nas sociedades fechadas, como a generalidade das sociedades anônimas brasileiras, a preocupação de quantos detêm a maioria das ações, é a da retenção dos lucros sob os mais variados títulos contabilísticos, evitando o pagamento dos dividendos aos acionistas em minoria a fim de forçá-los a abrir mão de suas ações. Aliảs, prática é essa generalizada em todo o mundo, como demonstram as recentes leis sôbre o anonimato, sem que logrem seu objetivo.

Sempre haverá como justificar a política da retenção dos lucros sob a forma de reservas explícitas e de reservas ocultas, a despeito da constante diligência nesse sentido dos agentes do fisco para a efetiva cobrança do imposto de renda. 
12. Ponto digno de relevância é que a lei brasíleira se apresentou excessivamente regulamentária.

Evitou com isso a legislação dos diretores por via dos estatutos sociais, em que se estabeleciam dispositivos draconianos para os acionistas em maioria; e assim é que tôda a matéria atinente às assembléias gerais, desde sua convocação até suas deliberações, se acha regulada pormenorizadamente. Constitui isso inequivoca garantia para os acionistas que efetivamente se interessem pela marcha dos negócios sociais. Nem todos são dessa categoria, senão meros aplicadores de capitais, desinteressados do sucesso industrial ou mercantil do empreendimento, mas preocupados apenas com a regularidade no pagamento dos dividendos semestrais ou de fim de ano.

Para evitar a concessão, pelos estatutos, de poderes excessivos à diretoria, em detrimento dos acionistas, teve a lei o cuidado de estabelecer a matéria de exclusiva competência da assembléia geral. Com isso, abusos constantes se evitaram, de molde a assegurar aos acionistas minoritários o direito de defender seus direitos com os da própria coletividade societária. Ação têm êles para anular a constituição da sociedade por vícios ou defeitos verificados naquele ato ou para anular as deliberações tomadas em assembléia geral ou especial, irregularmente convocada ou instalada, ou violadoras da lei ou dos estatutos, ou eivadas de êrro, dolo ou simulação; ou, ainda, para responsabilizar fundadores, diretores, fiscais ou liquidantes por atos cul. posos ou dolosos ou violadores da lei ou dos estatutos.

$O$ exercício dêsses direitos no entanto ficou adstrito a prazos curtos, de um a três anos, pela predominância do preconceito de que sobreleva a existência da sociedade, do ponto de vista do interêsse público, ao seu desaparecimento. Daí o ser lícito à sociedade, por deliberação da assembléia geral, providenciar para que saneie o vício ou defeito originário da ação destinada a anulá-la; e, em caso de dissolução e liquidação da sociedade, o poder a mesma assembléia, pelo voto de acionistas representando a metade, 
no mínimo, do capital social, fazer cessar o estado de liquidação, a fim de repôr a sociedade em sua vida normal. $\mathrm{E}$ isso é a ressurreição.

13. Outros e diversos aspectos da lei brasileira sôbre o estatuto das sociedades anônimas poderiam ser trazidos à sumariedade dêste estudo, que se acha limitado pela natureza desta publicação; e o debate poderia alongar-se sobremodo diante da deficiência das leis no atendimento das necessidades do comércio e da indústria, que se avantajam com o desenvolvimento de um e de outró, sob a égide das invenções e descobrimentos dos últimos tempos. 